NBER WORKING PAPER SERIES

\begin{abstract}
OPTIMAL INFLATION TARGETS, 'CONSERVATIVE' CENTRAL BANKS, AND LINEAR INFLATION CONTRACTS
\end{abstract}

Lars E. O. Svensson

Working Paper 5251

\author{
NATIONAL BUREAU OF ECONOMIC RESEARCH \\ 1050 Massachusetts Avenue \\ Cambridge, MA 02138 \\ September 1995
}

I have benefitted from discussions with and comments from Robert Barro, Claes Berg, Alan Blinder, Alex Cukierman, Jon Faust, Stanley Fischer, Stefan Gerlach, John Green, Dale Henderson, Berthold Herrendorf, Lars Hörngren, Peter Isard, Gunnar Jonsson, Leo Leiderman, Ben Lockwood, Torsten Persson, Andrew Rose, Paul Söderlind, Guido Tabellini, Carl Walsh, Janet Yellen, and participants in seminars at the CEPR European Summer Symposium in Macroeconomics, the Federal Reserve Board, and the International Monetary Fund. Remaining errors and obscurities are my own. I thank Molly Åkerlund and Maria Gil for secretarial assistance, and Stefan Palmqvist for research assistance. This paper is part of NBER's research programs in International Finance and Macroeconomics, and Monetary Economics. Any opinions expressed are those of the author and not those of the National Bureau of Economic Research.

() 1995 by Lars E. O. Svensson. All rights reserved. Short sections of text, not to exceed two paragraphs, may be quoted without explicit permission provided that full credit, including ( $)$ notice, is given to the source. 


\title{
OPTIMAL INFLATION TARGETS, 'CONSERVATIVE' CENTRAL BANKS, AND LINEAR INFLATION CONTRACTS
}

\begin{abstract}
Inflation target regimes (like those of New Zealand, Canada, U.K., Sweden and Finland) are interpreted as having explicit inflation targets and implicit output/unemployment targets. Without output/unemployment persistence, delegation of monetary policy to a discretionary instrument-independent central bank with an optimal inflation target can eliminate the discretionary inflation bias, mimic the optimal linear inflation contract suggested by Walsh and extended by Persson and Tabellini, and achieve the equilibrium corresponding to an optimal rule with commitment. Thus an 'inflation target-conservative' central bank with an inflation target equal to the socially best inflation rate less any inflation bias dominates a Rogoff 'weightconservative' central bank with increased weight on inflation stabilization, which suboptimally increases output/unemployment variability. With output/unemployment persistence, a constant inflation target is equivalent to a constant linear inflation contract. They can both eliminate the average inflation bias but not the state-contingent part of the inflation bias. Inflation variability is too high, and output variability too low, compared to the equilibrium corresponding to an optimal rule. An optimal state-contingent inflation target can remove all inflation bias, but in contrast to an optimal state-contingent linear inflation contract it still leaves inflation variability too high. Delegation with an optimal state-contingent inflation target to a Rogoff 'weightconservative' central bank can then achieve the equilibrium corresponding to an optimal rule. Inflation targets may on average be exceeded, and they may have imperfect credibility. Nevertheless they may usefully reduce inflation, and they appear much easier to implement than linear inflation contracts.
\end{abstract}

Lars E. O. Svensson

Institute for International Economic Studies

Stockholm University

S-106 91 Stockholm

SWEDEN

and NBER 


\section{Introduction}

Recently a number of countries-New Zealand, Canada, U.K., Sweden and Finlandhave introduced explicit inflation target monetary policy regimes. ${ }^{1}$ This paper attempts at understanding these regimes and their properties in relation to the literature on rules and discretion in monetary policy initiated by Kydland and Prescott (1977) and Barro and Gordon (1983).

According to the conventional wisdom that has emanated from that literature, the combination of discretionary monetary policy and a short-run benefit from surprise inflation, for instance due to distortions in the labor market that make the natural rate of unemployment inefficiently high, leads to a fourth-best equilibrium with an inflation bias relative to the second-best equilibrium resulting from a commitment to an optimal rule. ${ }^{2}$ Possible improvements to the discretionary equilibrium have been discussed extensively in the literature. An influential contribution by Rogoff (1985) has suggested delegation of monetary policy to an independent 'conservative' central bank, where 'conservative' means 'weight-conservative', putting more weight on inflation stabilization than society does. This reduces the inflation bias but brings higher than optimal output/unemployment variability and hence leads to a third-best equilibrium rather than the second best. Simple rules with escape clauses, like constant low inflation for small supply shocks and discretionary behavior for large shocks, have been examined by Flood and Isard (1989), Lohmann (1992) and Obstfeld (1991). These also lead to third-best equilibria rather than to the second best. An optimal central bank contract suggested by Walsh (1995a) and extended upon by Persson and Tabellini (1994) can achieve the second-best equilibrium, however. The contract, the "linear inflation contract," is in principle very simple and

\footnotetext{
${ }^{1}$ See the papers in Leiderman and Svensson (1995) as well as Ammer and Freeman (1995).

${ }^{2}$ Throughout the paper I follow Rogoff's (1985) consistent terminology and refer to the equilibrium corresponding to an optimal rule under commitment as a second-best equilibrium, where the natural level of output (unemployment) is lower (higher) then the socially desirable level, due to, for instance, some distortion in the labor market. The first-best equilibrium requires elimination of the distortion and the increase (decrease) of the natural level of output (unemployment) to the socially desirable level. The discretionary equilibrium is referred to as fourth-best, and equilibria ranked between the discretionary and the commitment equilibria are referred to as third-best. The alternative, used in some of the literature (and a previous version of this paper) is to refer to the commitment equilibria as the first best and the discretionary as the third best; with intermediate equilibria as second best.
} 
consists of adding a linear cost of inflation to the central bank's loss function, but its implementation presents several practical difficulties. ${ }^{3}$

The study of rules and discretion in monetary policy has been extended beyond the standard static framework to situations with persistence in output and unemployment. Results in Lockwood and Philippopoulos (1994), Jonsson (1995), and Lockwood, Miller and Zhang (1995) imply that discretion then leads to a state-contingent inflation bias relative to the second-best equilibrium resulting from an optimal rule under commitment. The inflation bias is on average larger than without persistence. Also, under discretion inflation variability becomes too high, and output and unemployment variability too low, relative to the second best. Currie, Levine and Pearlman (1995) and Lockwood, Miller and Zhang (1995) have examined third-best Rogoff delegation of monetary policy to a central bank which puts more weight on inflation stability than society does. Lockwood, Miller and Zhang have also shown that a state-contingent linear inflation contract can achieve the second-best equilibrium when there is persistence.

This paper examines the performance of inflation target regimes relative to these previous results, with and without persistence in output and unemployment. This then requires a theoretical representation of a stylized inflation target regime in the standard theoretical framework. An inflation target regime is interpreted here as a somewhat idealized delegation of monetary policy to a central bank.

The delegation is a commitment mechanism with three components: (1) The government assigns a loss function to the central bank which may deviate from the social loss function. (2) The central bank is given independence to minimize the assigned loss function without interference from the government or other interests. (3) The central bank is held accountable for minimizing the assigned loss function. Note that with such a delegation, the central bank is given instrument independence rather than goal independence. ${ }^{4}$

\footnotetext{
${ }^{3}$ See Canzoneri, Nolan and Yates (1995), Goodhart and Viñals (1994) and Walsh (1995b) for recent discussions of the Walsh and Persson-Tabellini results. See also Fratianni, von Hagen and Waller (1993) for further extensions of central banking as a principal-agent problem.

${ }^{4}$ Instrument independence (or operational independence) means that the central bank is free to select the best means to achieve a given goal for monetary policy. Goal independence means that the central bank is free to choose the goal of monetary policy. See Debell and Fischer (1994) and Stanely Fischer (1994) for further discussion of goal and instrument independence, and for further discussion of this kind of delegation of monetary policy.
} 
In the real world, the New Zealand inflation target regime is closest to this kind of delegation. ${ }^{5}$ In the other countries with inflation targets, the accountability of the central banks for achieving the targets is less explicit, since the targets in some cases are unilateral declarations of the central banks. ${ }^{6}$ The independence of the central banks is also less than in the New Zealand case. These differences are discussed further in the concluding section.

For concreteness, let me assume that the government and the society have preferences over inflation and output or unemployment that correspond to a quadratic social loss function over inflation, $\pi_{t}$, and output or unemployment, $y_{t}$, in period $t$,

$$
L_{t}=\frac{1}{2}\left[\left(\pi_{t}-\pi^{*}\right)^{2}+\lambda\left(y_{t}-y^{*}\right)^{2}\right]
$$

The loss function is characterized by three parameters: $\pi^{*}$ is the socially desirable inflation rate, $y^{*}$ is the socially desirable output or unemployment level, and $\lambda>0$ is the social weight on output/unemployment stabilization relative to inflation stabilization.

An inflation target regime is then interpreted as the delegation of monetary policy to the central bank as above, with an assigned loss function

$$
L_{t}^{b}=\frac{1}{2}\left[\left(\pi_{t}-\pi^{b}\right)^{2}+\lambda^{b}\left(y_{t}-y^{b}\right)^{2}\right]
$$

with the three parameters $\pi^{b}, y^{b}$ and $\lambda^{b}$ that may differ from the corresponding parameters of the social loss function. Thus, an inflation target regime is taken to have an explicit announced inflation target, $\pi^{b}$, an implicit output/unemployment target, $y^{b}$, and an $i m$ plicit relative weight on output/unemployment stabilization, $\lambda^{b}>0$. The interpretation of inflation target regimes as having a loss function involving both inflation and output/unemployment targets is supported by several circumstances (see the contributions in Leiderman and Svensson (1995)): (1) Actual inflation target regimes (with the exception of Finland) have explicit tolerance bands around the target level, indicating that some variability of inflation around the target is acceptable (Finland for sure has an implicit

This delegation of monetary policy is an example of general strategic delegation that has been discussed in the Industrial Organizations literature, cf. Ferstman and Judd (1987).

${ }^{5}$ See Ammer and Freeman (1995), Archer (1995) and Andreas Fischer (1995).

${ }^{6}$ See Leiderman and Svensson (1995, Introduction). 
tolerance band). (2) No central bank with an explicit inflation target seems to behave as if it wishes to achieve the target at all cost, regardless of the output/unemployment consequences. (3) Prominent central bankers, for instance King (1995), have interpreted inflation target regimes precisely in this way. Thus, an inflation target regime is not interpreted as corresponding to $\lambda^{b}=0$ in (1.2), what King (1995) calls the case of an "inflation nutter." An inflation target regime need not have explicit escape clauses for supply shocks in order to incorporate some preference for output and unemployment stabilization, counter to the interpretation in Stanley Fischer (1995b).

In the inflation target regimes to be discussed below the central bank will in the standard case be assumed to have the same output or unemployment target as the government, and the same relative weight on output/unemployment stabilization, although I shall report results also for different output/unemployment targets and different relative weights. ${ }^{7}$ The government will be assumed to have an output or unemployment target corresponding to less unemployment than the natural rate of unemployment, because, for instance, distortions in the labor market make the natural rate inefficiently high. The role of this output or unemployment target in the analysis is to introduce a benefit from a surprise inflation. As noted in the literature, such benefits can arise also for other reasons, for instance, if a surprise real depreciation of the nominal public debt is less distortionary than explicit taxation. Thus the loss function assigned to the central bank will in the standard case have an 'overambitious' output or unemployment target, which under discretion results in an inflation bias. A more rational delegation of monetary policy would assign an output/unemployment target corresponding to the natural rate of unemployment. ${ }^{8}$ Such a rational delegation is assumed infeasible in the standard case, for instance, because of political difficulties in delegating an output target corresponding to less than full employment, or difficulties in verifying the delegation of a natural unemployment rate, or lack of unanimity of estimates of the natural unemployment rate. The assumption reflects

\footnotetext{
${ }^{7}$ I will assume throughout that the central bank's discount factor is the same as the government's.

${ }^{8}$ There is, of course, nothing irrational in the government having an unemployment target lower than the natural rate of unemployment, if the natural rate of unemployment is inefficient and due to distortions. Such an ambitious unemployment target is then appropriate for, for instance, structural labor market policy. The irrationality is in assigning such an unemployment target to monetary policy.
} 
the general temptation in monetary policy to err on the lax side, if only because raising interest rates is (politically) unpopular, and lowering interest rates is popular. ${ }^{9}$ However, as we shall see, even if the output/unemployment target would be fixed at the long-run natural rate level, if there is persistence in output and unemployment only the average discretionary inflation bias is eliminated and there will still be a state-contingent inflation bias, as well as too high inflation variability relative to the second-best equilibrium. ${ }^{10}$ In the concluding section I shall discuss further the p3ossibilit of delegating a more rational output or unemployment target in an inflation target regime.

Given this interpretation of an inflation target regime as having an explicit inflation target, an implicit output/unemployment target and an implicit relative weight on output/unemployment stabilization, I shall examine the performance of such a regime both in the static case without output and unemployment persistence and in the dynamic case with persistence. For instance, without persistence an inflation target regime with an inflation target will be equivalent to a linear inflation contract. It can hence achieve the second-best equilibrium and is better than third-best Rogoff delegation to a 'weight-conservative' central bank. With persistence, a inflation target regime is not quite identical to a linear inflation contract. A combination of an optimal state-contingent inflation target and a 'weight-conservative' central bank can still achieve the second-best equilibrium, though.

Section 3 and 4 deal, respectively, with the case without and with output persistence. Section 5 summarizes the results and concludes. An appendix contains some technical results.

\footnotetext{
${ }^{9}$ Goodhart (1995, p.1426-1427): 'Even without political subservience, there will usually be a case for deferring interest rate increases, until more information on current developments becomes available. Politicians do not generally see themselves as springing surprise inflation on the electorate. Instead, they suggest that an electorally inconvenient interest rate increase should be deferred, or a cut 'safely' accelerated. But it amounts to the same thing in the end.'

${ }^{10}$ Lockwood and Philippopoulos (1994) have shown that a state-contingent inflation bias results when the unemployment target equals the natural rate of unemployment.
} 


\section{No output persistence}

The model has three agents: the private sector, the government and the central bank. The private sector behavior is characterized by an aggregate supply function and rational expectations. The aggregate supply function is given by

$$
y_{t}=\alpha\left(\pi_{t}-\pi_{t}^{e}\right)+\epsilon_{t},
$$

where $y_{t}$ is (the $\log$ of) output in period $t, \alpha$ is a positive constant, $\pi_{t}$ is the (log of the gross) inflation rate, $\pi_{t}^{e}$ denotes inflation expectations in period $t-1$ of the inflation rate in period $t$, and $\epsilon_{t}$ is an i.i.d. supply shock with mean 0 and variance $\sigma^{2}$. The private sector has rational expectations. That is,

$$
\pi_{t}^{e}=\mathrm{E}_{t-1} \pi_{t},
$$

where $\mathrm{E}_{t-1}$ denotes expectations conditional upon information available in period $t-1$, which includes the realization of all variables up to and including period $t-1$, as well as the constant parameters of the model. The supply function corresponds, for instance, to a situation in which nominal wages for period $t$ are set one period in advance, based on inflation expectations in period $t-1$, without knowing the supply shock $\epsilon_{t}$ in period $t$. The (long-run) natural output level, which I identify with the unconditional mean of output, $\mathrm{E}\left[y_{t}\right]$, is for convenience set equal to zero.

The government's preferences are assumed to be the same as the social preferences. The analysis will be normative, in that the social preferences will be used to evaluate the different equilibria. ${ }^{11}$ The social preferences are assumed to concern inflation and output, the latter under the assumption that output is linearly related to unemployment. To the extent that output, employment and unemployment are not linearly related, social preferences probably concern unemployment. Then the analysis can easily be done in terms of unemployment instead of output.

\footnotetext{
${ }^{11}$ The analysis could be descriptive rather than normative, if the government's preferences are taken as given without necessarily coinciding with social preferences.
} 
The social preferences are represented by the social loss function

$$
V=\mathrm{E}_{0}\left[\sum_{t=1}^{\infty} \beta^{t-1} L_{t}\right]
$$

with the "period" loss function (1.1) and the discount factor $\beta, 0<\beta<1 .{ }^{12}$ The (log of the) socially desirable output level, $y^{*}$, is assumed to exceed the natural output level and hence fulfills $y^{*}>0$. Then $y^{*}$ can be interpreted as a measure of the distortion in the labor market that causes the socially desirable (full employment) output level to exceed the natural output level. Alternatively $y^{*}$ can be interpreted as a measure of the extent to which the output target is overambitious. The role of the overambitious output target in the analysis is to introduce a benefit from inflation surprises.

The central bank is for simplicity assumed to have perfect control over the inflation rate $\pi_{t}$. It sets the inflation rate in each period after having observed the current supply shock $\epsilon_{t} \cdot{ }^{13}$

\subsection{Commitment to an optimal rule}

Consider first the situation when the central bank is directly controlled by the government, so the government can choose the inflation rate in each period, conditional upon the supply shock in the period. Assume furthermore that the government can commit to a statecontingent rule for the inflation rate. Since there is no output persistence, the problem of minimizing the intertemporal loss function (2.3) is equivalent to the static problem

\footnotetext{
${ }^{12}$ I follow Persson and Tabellini (1990) and put the weight $\lambda$ on the squared output term, since the expressions become somewhat simpler then. Rogoff puts the weight $\chi$ on the squared inflation term. Lockwood and Philippopoulos (Lockwood, Miller and Zhang) put the symmetric weights $\lambda$ and $1-\lambda$ on the squared output (inflation) and inflation (output) terms, respectively. Decision rules are easily translated by replacing $\lambda$ by $1 / \chi$ or $\lambda /(1-\lambda)(1-\lambda / \lambda)$. Translation of loss functions and their parameters must also take into account the implicit scaling of the loss function.

Many papers simplify the supply function (2.1) by setting $\alpha=1$. This normalization is equivalent to scaling inflation by $\alpha$ and hence by scaling the parameter $\lambda$ and the loss function by $\alpha^{2}$. I prefer to keep the $\alpha$ since that simplifies assessing the restrictiveness of two existence conditions that arise with output persistence.

${ }^{13}$ The results are not affected in any essential way if an error term is added on inflation, indicating imperfect control of inflation. Neither are the results affected if output is considered the control variable; or (cf. Rogoff (1985)) if an aggregate demand equation is also added where aggregate demand depends on the real interest rate and the nominal interest rate is the instrument of monetary policy; or if a money demand equation is also added and money supply is the instrument.
} 
of minimizing the expected period loss function (1.1). Following Persson and Tabellini (1994) it can be formulated as the problem

$$
\min _{\pi_{t}, \pi_{\ell}^{e}} E\left[L_{t}\right],
$$

subject to (2.1) and (2.2). Thus the government chooses $\pi_{t}$, which will depend on $\epsilon_{t}$, and inflation expectations $\pi_{t}^{e}$, which must not depend on $\epsilon_{t}$, subject to the condition that inflation expectations are rational, (2.2). Put differently, the government internalizes the effects of its decision rule on expectations.

The first order condition with respect to $\pi_{t}$ and $\pi_{t}^{e}$ are, respectively,

$$
\begin{gathered}
\pi_{t}-\pi^{*}+\lambda \alpha\left(y_{t}-y^{*}\right)+\theta_{t-1}=0 \\
-\mathrm{E}_{t-1}\left[\lambda \alpha\left(y_{t}-y^{*}\right)\right]-\theta_{t-1}=0
\end{gathered}
$$

where $\theta_{t-1}$ is the Lagrange multiplier of (2.2). Eliminating the multiplier gives

$$
\pi_{t}-\pi^{*}+\lambda \alpha\left(y_{t}-y^{*}\right)-\mathrm{E}_{t-1}\left[\lambda \alpha\left(y_{t}-y^{*}\right)\right]=0,
$$

Taking expectations at $t-1$ of (2.5) results, with (2.2), in

$$
\mathrm{E}_{t-1} \pi_{t}=\pi^{*}
$$

Combining (2.1), (2.2), (2.5) and (2.6) gives the optimal decision rule

$$
\pi_{t}=a-b \epsilon_{t}
$$

with

$$
a=\pi^{*} \quad \text { and } \quad b=\frac{\lambda \alpha}{1+\lambda \alpha^{2}} .
$$

With (2.7) output will fulfill

$$
y_{t}=(1-\alpha b) \epsilon_{t},
$$


and the optimal output response is

$$
y_{t}=\frac{1}{1+\lambda \alpha^{2}} \epsilon_{t}
$$

The average inflation rate $\mathrm{E}\left[\pi_{t}\right]$ will equal the socially desirable inflation rate $\pi^{*}$. The average output equals the natural output level, 0 . Inflation decreases with the supply shock; in order to dampen the supply shock's effect on output and achieve the optimal relative variability of output and inflation. The optimal value of (2.3) will be given by

$$
V=\frac{1}{1-\beta} \mathrm{E}\left[L_{t}\right]=\frac{1}{1-\beta} \frac{1}{2}\left(\lambda y^{* 2}+\frac{\lambda}{1+\lambda \alpha^{2}} \sigma^{2}\right) .
$$

\subsection{Discretion}

Assume now that the government retains direct control of the central bank, but that the government cannot commit to a state-contingent rule. Instead it acts under discretion. Then the government chooses $\pi_{t}$ in each period $t$ so as to minimize the period loss function $L_{t}$ subject to (2.1), but for given inflation expectations, $\pi_{t}^{e}$. The government no longer internalizes the effect of its decision rule on inflation expectations. The first order condition is then

$$
\pi_{t}-\pi^{*}+\lambda \alpha\left(y_{t}-y^{*}\right)=0 .
$$

Taking expectations at $t-1$ gives, with (2.2),

$$
\mathrm{E}_{t-1} \pi_{t}=\pi^{*}+\lambda \alpha y^{*}
$$

Combining (2.1), (2.2), (2.12) and (2.13) results in a decision rule (2.7) with

$$
a=\pi^{*}+\lambda \alpha y^{*}
$$

and $b$ given by (2.8). Average inflation is now

$$
\mathrm{E}\left[\pi_{t}\right]=\pi^{*}+\lambda \alpha y^{*}
$$


and exceeds the socially optimal inflation rate by the inflation bias $\lambda \alpha y^{*}$. Output still behaves according to (2.10), average output is equal to the natural rate, and the variances of inflation and output are the same as under the optimal rule. The social loss (2.3) is

$$
V=\frac{1}{1-\beta} \frac{1}{2}\left(\lambda y^{* 2}+\lambda^{2} \alpha^{2} y^{* 2}+\frac{\lambda}{1+\lambda \alpha^{2}} \sigma^{2}\right)
$$

and it exceeds the optimal social loss (2.11) by the term $\frac{1}{1-\beta} \frac{1}{2} \lambda^{2} \alpha^{2} y^{* 2}, \frac{1}{1-\beta}$ times half the square of the inflation bias.

Thus, with an output target that exceeds the natural output level, discretion results in a fourth-best equilibrium with too high inflation. Commitment to an optimal state-contingent rule would improve the situation and achieve the second-best equilibrium. Since commitment to a state-contingent rule appears infeasible (see for instance the discussion in Laidler (1993)), the literature has suggested other improvements of the discretionary equilibrium.

If the natural output level is below the socially desirable output level because of distortions (in the labor market, say), an obvious improvement, suggested in Rogoff (1985), is to remove the distortions and increase the natural output level to the socially desirable output level. This would remove the inflation bias under discretion and with the increase in output result in a first-best equilibrium. If such distortions cannot be removed, other improvements have to be found, which at most will result in a second-best equilibrium. I now consider delegation to an instrument-independent central bank, as discussed in the Introduction.

\subsection{Delegation to a 'weight-conservative' central bank}

Rogoff (1985) has shown that the discretionary equilibrium can be improved if monetary policy is delegated to a 'weight-conservative' central bank with more weight on inflation stabilization than the government. This can be interpreted as the government delegating monetary policy to a central bank with both goal and instrument independence, and that the government can observe potential Governor's or Board's preferences and can select a Governor or Board with the desired preferences. Alternatively, it can be interpreted as 
a delegation to an instrument-independent central bank that is assigned a particular loss function. This is the interpretation given here. Thus, the central bank is given the period loss function

$$
L_{t}^{b}=\frac{1}{2}\left[\left(\pi_{t}-\pi^{*}\right)^{2}+\lambda^{b}\left(y_{t}-y^{*}\right)^{2}\right]
$$

where $\lambda^{b}$ differs from $\lambda$ in social loss function (2.3). Rogoff's result is then that there exists a $\lambda^{b}, 0<\lambda^{b}<\lambda$, that achieves a lower value of society's loss function (2.3) than (2.16). The central bank's decision rule (2.7) then has

$$
a=\pi^{*}+\lambda^{b} \alpha y^{*} \quad \text { and } \quad b=\frac{\lambda^{b} \alpha}{1+\lambda^{b} \alpha^{2}}
$$

Compared to the optimal rule (2.8) there is still an inflation bias, $\lambda^{b} \alpha y^{*}$, but the inflation bias is lower. The inflation response to the supply shock is smaller than the optimal one, and the output response is larger. Thus, the lower inflation bias comes at the cost of increased output variability. The second-best equilibrium cannot be achieved. ${ }^{14}$

\subsection{A linear inflation contract}

Walsh (1995a) has shown that a simple linear inflation contract for the central bank can remove the inflation bias under discretion without any increase in output variability. Thus the second-best equilibrium can be achieved. The contract adds a linear cost to inflation to the social period loss function. Let the added linear cost to inflation be $f\left(\pi_{t}-\pi^{*}\right)$, where $f$ is constant. Then the central bank is assigned the period loss function

$$
L_{t}^{b}=\frac{1}{2}\left[\left(\pi_{t}-\pi^{*}\right)^{2}+\lambda\left(y_{t}-y^{*}\right)^{2}\right]+f\left(\pi_{t}-\pi^{*}\right) .
$$

If we assume that the central bank shares the social loss function (2.3), this can in principle be achieved by giving the central bank an additional cost $f\left(\pi_{t}-\pi^{*}\right)$ to pay. The first-order condition is

$$
\pi_{t}-\pi^{*}+\lambda \alpha\left(y_{t}-y^{*}\right)+f=0
$$

\footnotetext{
${ }^{14}$ Lockwood, Miller and Zhang (1995) provide a very elegant treatment of Rogoff delegation, including the case with unemployment persistence.
} 
The resulting decision rule (2.7) will have

$$
a=\pi^{*}+\lambda \alpha y^{*}-f
$$

whereas $b$ is given by (2.8). It is clear that, if $f$ equals the inflation bias,

$$
f=\lambda \alpha y^{*},
$$

the second-best equilibrium will be achieved.

\subsection{An explicit inflation target}

Consider now assigning explicit inflation and output targets $\pi^{b}$ and $y^{b}$ to the central bank. The targets may differ from the socially desirable inflation rate and output level. Furthermore, let this assignment be with the understanding that the weight $\lambda$ on output stabilization will be the same as in the social loss function. Then the central bank is assigned the period loss function

$$
L_{t}^{b}=\frac{1}{2}\left[\left(\pi_{t}-\pi^{b}\right)^{2}+\lambda\left(y_{t}-y^{b}\right)^{2}\right]
$$

The central bank's decision rule (2.7) will have

$$
a=\pi^{b}+\lambda \alpha y^{b}
$$

whereas $b$ will be given by (2.8). Clearly, the variance of inflation and output will be the same as under the optimal rule. Furthermore, if the target inflation rate and target output are chosen so as to fulfill

$$
\pi^{b}+\lambda \alpha y^{b}=\pi^{*}
$$

the equilibrium will be the same as for the optimal rule, and the second-best situation can be reached. In particular, if the implicit output target is the same as society's, the 
inflation target should simply be chosen so as to equal the socially desirable inflation rate less the inflation bias under discretion,

$$
\pi^{b}=\pi^{*}-\lambda \alpha y^{*}
$$

Alternatively, if the central bank's output target coincides with the natural output level, its inflation target should equal the socially desirable inflation rate, since then the inflation bias under discretion vanishes. ${ }^{15}$

Thus, delegating monetary policy to a central bank with an explicit inflation target according to (2.22) but with an unchanged weight on inflation/output stabilization and an unchanged output target is better than delegating to a central bank with relative more weight on inflation stabilization. That is, having an 'inflation-target-conservative' central bank is better than having a 'weight-conservative' central bank. Canzoneri (1985) has extended the Barro and Gordon (1983) and Rogoff (1985) framework to a situation when the central bank has private information. Also in that case the inflation bias resulting under discretion can be eliminated, without adverse effects on output variability, by giving the central bank a lower inflation target. ${ }^{16}$

It is easy to see that an optimal inflation target (2.22) is equivalent to a optimal linear inflation contract (2.19). Starting from (2.20) with, for simplicity, $y^{b}=y^{*}$, we get

$$
\begin{gathered}
L_{t}^{b}=\frac{1}{2}\left[\left(\pi_{t}-\pi^{b}\right)^{2}+\lambda\left(y_{t}-y^{*}\right)^{2}\right]=\frac{1}{2}\left[\left(\left(\pi_{t}-\pi^{*}\right)+\left(\pi^{*}-\pi^{b}\right)\right)^{2}+\lambda\left(y_{t}-y^{*}\right)^{2}\right] \\
=\frac{1}{2}\left[\left(\pi_{t}-\pi^{*}\right)^{2}+\lambda\left(y_{t}-y^{*}\right)^{2}+2\left(\pi_{t}-\pi^{*}\right)\left(\pi^{*}-\pi^{b}\right)+\left(\pi^{*}-\pi^{b}\right)^{2}\right] \\
=L_{t}+\left(\pi^{*}-\pi^{b}\right)\left(\pi_{t}-\pi^{*}\right)+\frac{1}{2}\left(\pi^{*}-\pi^{b}\right)^{2} .
\end{gathered}
$$

Hence, the inflation target loss function $L_{t}^{b}$ differs from $L_{t}$, the social period loss function,

\footnotetext{
${ }^{15}$ Persson and Tabellini $(1990$, p. $27, n .18)$ note that reducing the output target to the natural output level would remove the inflation bias.

${ }^{16}$ Thus, I agree with McCallum (1995) that there need not necessarily be a trade-off between flexibility and commitment, but for very different reasons!
} 
by a term that is linear in $\pi_{t}$ and a constant. Thus, if $\pi^{b}$ is chosen to fulfill

$$
\pi^{*}-\pi^{b}=f=\lambda \alpha y^{*}
$$

the inflation target and the linear inflation contract are equivalent.

\section{Output persistence}

To allow for persistence is a natural extension of the aggregate supply function (2.1). The literature on rules and discretion has only recently incorporated this extension (see Lockwood and Philippopoulos (1994), Jonsson (1995) and Lockwood, Miller and Zhang (1995)). With output persistence the aggregate supply function is

$$
y_{t}=\rho y_{t-1}+\alpha\left(\pi_{t}-\pi_{t}^{e}\right)+\epsilon_{t}
$$

where $0 \leq \rho<1$. The autoregressive term arises, for instance, in wage setting models where trade unions set nominal wages one period in advance, disregarding non-union workers' preferences and only taking into account union members' preferences for real wages and employment, and where union membership depends on previous unemployment. ${ }^{17}$ Output persistence will introduce lagged output as a state variable, which will be important for the relations between the optimal rule under commitment, linear inflation contracts and inflation targets. The equilibrium under discretion has been studied by Lockwood and Philippopoulos (1994) for the infinite-horizon case. The optimal rule under commitment and the decision rule under discretion are compared in Jonsson (1995) for the two-period case and in Lockwood, Miller and Zhang (1995) for the infinite horizon case.

\footnotetext{
${ }^{17}$ Peristence of unemployment in such trade union models has been studied by Gottfries and Horn (1987) and Blanchard and Summers (1986).
} 


\subsection{Commitment to an optimal rule}

As in Lockwood, Miller and Zhang (1995), the optimal rule under commitment is derived as the solution to the problem

$$
V\left(y_{t-1}\right)=\min _{\pi_{t}, \pi_{t}^{e}} E_{t-1}\left\{\frac{1}{2}\left[\left(\pi_{t}-\pi^{*}\right)^{2}+\lambda\left(y_{t}-y^{*}\right)^{2}\right]+\beta V\left(y_{t}\right)\right\}
$$

subject to (3.1) and (2.2). This problem differs from the problem (2.4) in that lagged output enters as a state variable.

The first order conditions with respect to $\pi_{t}$ and $\pi_{t}^{e}$ result in

$$
\left(\pi_{t}-\pi^{*}\right)+\lambda \alpha\left(y_{t}-y^{*}\right)+\beta \alpha V_{y}\left(y_{t}\right)-\mathrm{E}_{t-1}\left[\lambda \alpha\left(y_{t}-y^{*}\right)+\beta \alpha V_{y}\left(y_{t}\right)\right]=0
$$

where the Lagrange multiplier of (2.2) has been eliminated. The first term is the marginal current loss from increasing inflation, the second is the marginal current loss from the resulting increase in output (normally negative since output is normally below $y^{*}$ ), the third is the discounted expected marginal future loss of the resulting increase in output (normally negative since higher output in the future is normally beneficial), and the fourth is the marginal loss of the resulting increase in expected inflation (normally positive since increased inflation expectations reduce output).

Taking expectations at $t-1$ of (3.3) gives

$$
\mathrm{E}_{t-1} \pi_{t}=\pi^{*}
$$

the expected inflation rate equals the socially desirable inflation rate and is independent of the output level.

Since the problem is linear-quadratic, we know that $V\left(y_{t-1}\right)$ must be quadratic. Then I can write

$$
V(y)=\gamma_{0}+\gamma_{1} y+\frac{1}{2} \gamma_{2} y^{2} \text { and } \quad V_{y}(y)=\gamma_{1}+\gamma_{2} y
$$

where the coefficients $\gamma_{0}, \gamma_{1}$ and $\gamma_{2}$ need to be determined (I will only be interested in $\gamma_{1}$ and $\left.\gamma_{2}\right)$. Since $V_{y}\left(y_{t}\right)$ is linear in $y_{t}$ we realize that the optimal rule can be written as a 
linear feedback rule for $\pi_{t}$ on $y_{t}$. I will prefer to write the optimal rule as an equilibrium function of $\epsilon_{t}$, though. Substitution of (3.1), (2.2), (3.4) and (3.5) into (3.3) results in a decision rule (2.7) with

$$
a=\pi^{*} \quad \text { and } \quad b=\frac{\left(\lambda+\beta \gamma_{2}\right) \alpha}{1+\left(\lambda+\beta \gamma_{2}\right) \alpha^{2}}
$$

Output will then fulfill

$$
y_{t}=\rho y_{t-1}+(1-\alpha b) \epsilon_{t}
$$

In order to find $b, \gamma_{2}$ has to be determined. I therefore apply the envelope theorem on (3.2), which together with (3.5) results in

$$
\begin{aligned}
V_{y}\left(y_{t-1}\right) & =\gamma_{1}+\gamma_{2} y_{t-1}=\mathrm{E}_{t-1}\left\{\left[\lambda\left(y_{t}-y^{*}\right)+\beta V_{y}\left(y_{t}\right)\right] \rho\right\} \\
& =-\left(\lambda y^{*}-\beta \gamma_{1}\right) \rho+\left(\lambda+\beta \gamma_{2}\right) \rho^{2} y_{t-1} .
\end{aligned}
$$

Identification of $\gamma_{1}$ and $\gamma_{2}$ gives

$$
\gamma_{1}=-\frac{\lambda \rho y^{*}}{1-\beta \rho} \quad \text { and } \quad \gamma_{2}=\frac{\lambda \rho^{2}}{1-\beta \rho^{2}}
$$

Using this in (3.6) results in

$$
b=b^{*}=\frac{\lambda \alpha}{1+\lambda \alpha^{2}-\beta \rho^{2}} .
$$

Comparing (2.8) and (3.10) we see that the optimal inflation response to supply shocks is larger under persistence than without. Since the supply shock has future as well as current effects on output it becomes more important to stabilize output; hence inflation is allowed to fluctuate more. 


\subsection{Discretion}

Under discretion the decision problem of the government/central bank can be written

$$
V\left(y_{t-1}\right)=\mathrm{E}_{t-1} \min _{\pi_{t}}\left\{\frac{1}{2}\left[\left(\pi_{t}-\pi^{*}\right)^{2}+\lambda\left(y_{t}-y^{*}\right)^{2}\right]+\beta V\left(y_{t}\right)\right\}
$$

where the minimization in period $t$ is subject to (3.1) but is done for given inflation expectations $\pi_{t}^{e}{ }^{18}$ The government/central bank thus no longer internalizes the effect of its decisions on inflation expectations, although it takes into account that changes in current output will affect current expectations of future inflation (this is incorporated in $\left.V\left(y_{t}\right)\right)$.

The first order condition will be

$$
\pi_{t}-\pi^{*}+\lambda \alpha\left(y_{t}-y^{*}\right)+\beta \alpha V_{y}\left(y_{t}\right)=\pi_{t}-\pi^{*}+\left(\lambda+\beta \gamma_{2}\right) \alpha y_{t}-\left(\lambda y^{*}-\beta \gamma_{1}\right) \alpha=0
$$

where I have used (3.5). The marginal loss of increased inflation expectations have vanished from the first-order condition. We also see that the decision rule can, as above, be written as a feedback rule for inflation on current output. I still prefer to express the decision rule as a function of the supply shock, though. Since past output will be a state-variable in the problem, the decision rule will also be a function of past output.

Taking expectations of (3.12) gives

$$
\mathrm{E}_{t-1} \pi_{t}=\pi^{*}+\left(\lambda y^{*}-\beta \gamma_{1}\right) \alpha-\left(\lambda+\beta \gamma_{2}\right) \alpha \rho y_{t-1}
$$

Adding (3.12) and (3.13), using (3.1) and (2.2), gives a decision rule $(a, b, c)$ of the form

$$
\pi_{t}=a-b \epsilon_{t}-c y_{t-1}
$$

\footnotetext{
${ }^{18}$ Since the minimization is done for each $t$ after observing the supply shock, min $_{\pi_{1}}$ is moved inside the expectations operator.
} 
with

$$
a=\pi^{*}+\left(\lambda y^{*}-\beta \gamma_{1}\right) \alpha, \quad b=\frac{\left(\lambda+\beta \gamma_{2}\right) \alpha}{1+\left(\lambda+\beta \gamma_{2}\right) \alpha^{2}} \quad \text { and } \quad c=\left(\lambda+\beta \gamma_{2}\right) \alpha \rho
$$

In order to find $\gamma_{1}$ and $\gamma_{2}$ I apply the envelope theorem to (3.11), which gives

$$
\begin{aligned}
& V_{y}\left(y_{t-1}\right)=\gamma_{1}+\gamma_{2} y_{t-1}=\mathrm{E}_{t-1}\left\{\left[\lambda\left(y_{t}-y^{*}\right)+\beta\left(\gamma_{1}+\gamma_{2} y_{t}\right)\right]\left[\rho-\alpha \frac{\partial \mathrm{E}_{t-1} \pi_{t}}{\partial y_{t-1}}\right]\right\}= \\
& -\left[\left(\lambda y^{*}-\beta \gamma_{1}\right)\left(\rho+\alpha^{2} \rho\left(\lambda+\beta \gamma_{2}\right)\right)\right]+\left[\left(\lambda+\beta \gamma_{2}\right) \rho^{2}+\alpha^{2} \rho^{2}\left(\lambda+\beta \gamma_{2}\right)^{2}\right] y_{t-1},
\end{aligned}
$$

where I have remembered to take into account that changes in $y_{t-1}$ have effects on $y_{t}$ via their effects on inflation expectations according to (3.13),

$$
\frac{\partial \mathrm{E}_{t-1} \pi_{t}}{\partial y_{t-1}}=-\left(\lambda+\beta \gamma_{2}\right) \alpha \rho
$$

Identifying the coefficient for $y_{t-1}$ gives

$$
\gamma_{2}=\rho^{2}\left(\lambda+\beta \gamma_{2}\right)+\alpha^{2} \rho^{2}\left(\lambda+\beta \gamma_{2}\right)^{2}
$$

This is a second-degree equation in $\gamma_{2}$, which hence has two potential roots. Using the expression for $c$ in (3.15) the equation can be written in terms of $c$ as

$$
c=\lambda \alpha \rho+\beta \rho^{2} c+\beta \alpha \rho c^{2} .
$$

The equation has real solutions if and only if the first existence condition

$$
\lambda \leq \bar{\lambda}_{1}=\frac{\left(1-\beta \rho^{2}\right)^{2}}{4 \beta \alpha^{2} \rho^{2}}
$$

holds. In the appendix it is shown that only the smaller solution is relevant (see also Lockwood \& Philippopoulos (1994)),

$$
\hat{c}=\frac{1}{2 \beta \alpha \rho}\left[1-\beta \rho^{2}-\sqrt{\left(1-\beta \rho^{2}\right)^{2}-4 \lambda \beta \alpha^{2} \rho^{2}}\right]>0 .
$$


From (3.15) $\gamma_{2}$ can be expressed in terms of $\hat{c}$. From (3.16) $\gamma_{1}$ can be expressed in terms of $\gamma_{2}$. Then $\gamma_{1}$ and $\gamma_{2}$ are given by

$$
\gamma_{1}=-\frac{\lambda y^{*}(\rho+\alpha \hat{c})}{1-\beta \rho-\beta \alpha \hat{c}}<0 \quad \text { and } \quad \gamma_{2}=\frac{\hat{c}-\lambda \alpha \rho}{\beta \alpha \rho}=\frac{\lambda \rho^{2}+\hat{c}^{2}}{1-\beta \rho^{2}}>0
$$

where (3.18) has been used to rewrite $\gamma_{2}$, to facilitate comparison with (3.9). We clearly have $\gamma_{2}>0$. But in order to ensure that there is a finite solution to $\gamma_{1}$ we must assume the second existence condition

$$
\beta(\rho+\alpha \hat{c})<1
$$

This condition does not follow from (3.19) but has to be assumed separately. (In the appendix it is shown that the condition is, for instance, violated for $\beta>\frac{1}{2}$ when $\lambda=\bar{\lambda}$ and $\rho \rightarrow 1$, even if (3.19) holds.) The condition has a natural interpretation: The expression $\beta(\rho+\alpha \hat{c})$ is the discounted total increase in output in period $t$ of a unit increase in output in period $t-1$, when inflation in period $t$ is held constant. The total effect consists of the direct effect, $\rho$, and the indirect effect via reduced inflation expectations, $\alpha \hat{c}$. If this discounted effect is above unity, the present value of the effect in all future periods will be unbounded.

From (3.22) and (3.20) follows that the second existence condition is equivalent to the condition

$$
\lambda<\bar{\lambda}_{2}=\frac{(1-\beta \rho)(1-\rho)}{\beta \alpha^{2} \rho} .
$$

It can indeed be shown that (3.23) is at least as restrictive as (3.19) (see the appendix),

$$
\bar{\lambda}_{2} \leq \bar{\lambda}_{1}
$$

Thus, the second existence condition is the binding one. Only if $y^{*}=0$, in which case $\gamma_{1}=0$, is the second existence condition irrelevant. ${ }^{19}$

If $\alpha$ in (3.1) equals unity, as in Lockwood and Philippopoulos (1994) and in Lockwood, Miller and Zhang (1995), the existence conditions appears rather restrictive. If $\beta=0.95$

\footnotetext{
${ }^{19}$ The conditions (3.22) and (3.23) do not appear in the analysis of Lockwood and Philippopoulos (1994) since they assume that $y^{*}=0$.
} 
and $\rho=0.4(0.8), \bar{\lambda}_{2}=0.98(0.06)$, respectively. If $\alpha$ instead equals 0.2 , the corresponding $\bar{\lambda}_{2}$ values are 25 times larger, that is, $24.5(1.58){ }^{20}$

From (3.15) and (3.21) then follows that the decision rule is $(\hat{a}, \hat{b}, \hat{c})$, with

$$
\hat{a}=\pi^{*}+\frac{\lambda \alpha y^{*}}{1-\beta \rho-\beta \alpha \hat{c}}, \quad \hat{b}=\frac{\lambda \alpha+\beta \alpha \hat{c}^{2}}{1+\lambda \alpha^{2}-\beta \rho^{2}+\beta \alpha^{2} \hat{c}^{2}}
$$

and $\hat{c}$ given by $(3.20)$.

Without persistence, under discretion the inflation response to supply shocks is the same as the optimal rule. With persistence, comparing (3.25) and (3.10) we see that under discretion the inflation response to supply shocks is larger than the optimal rule. Since under discretion the future inflation bias depends on current output, it becomes even more important to stabilize output, which requires a stronger inflation response.

We see that the inflation bias, $\hat{a}-\hat{c} y_{t-1}-\pi^{*}$, depends on past output and is hence state-dependent. The average inflation bias,

$$
\hat{a}-\pi^{*}=\frac{\lambda \alpha y^{*}}{1-\beta \rho-\beta \alpha \hat{c}}
$$

is larger than the inflation bias $\lambda \alpha y^{*}$ without output persistence.

\subsection{A constant linear inflation contract}

Consider first delegation to a central bank with a constant linear inflation contract, that is, when the added cost of inflation has a constant marginal cost of inflation which does not depend on past output. Then the central bank's period loss function is

$$
L_{t}^{b}=\frac{1}{2}\left[\left(\pi_{t}-\pi^{*}\right)^{2}+\lambda\left(y_{t}-y^{*}\right)^{2}\right]+f\left(\pi_{t}-\pi^{*}\right)
$$

where $f$ is constant. The decision problem is

$$
V^{b}\left(y_{t-1}\right)=\mathrm{E}_{t-1} \min _{\pi_{i}}\left\{\frac{1}{2}\left[\left(\pi_{t}-\pi^{*}\right)^{2}+\lambda\left(y_{t}-y^{*}\right)^{2}\right]+f\left(\pi_{t}-\pi^{*}\right)+\beta V^{b}\left(y_{t}\right)\right\}
$$

\footnotetext{
${ }^{20}$ The corresponding values for $\bar{\lambda}_{1}$ are $1.18(0.06)$ for $\alpha=1$, and $29.6(1.58)$ for $\alpha=0.2$.
} 
The first order condition will be

$$
\pi_{t}-\pi^{*}+\lambda \alpha\left(y_{t}-y^{*}\right)+f+\beta \alpha V_{y}^{b}\left(y_{t}\right)=0
$$

The envelope theorem applied to (3.26) gives (3.16). It follows that the only change in the equilibrium (3.25) is that the decision rule (3.14) will have

$$
a=\pi^{*}+\frac{\lambda \alpha y^{*}}{1-\beta \rho-\beta \alpha \hat{c}}-f
$$

Hence, by choosing

$$
f=-\frac{\lambda \alpha y^{*}}{1-\beta \rho-\beta \alpha \hat{c}}
$$

the average inflation bias can be eliminated, and the decision rule will be $\left(\pi^{*}, \hat{b}, \hat{c}\right)$. A constant linear inflation contract can eliminate the average inflation bias, but it cannot achieve the optimal rule. The inflation bias will be state-dependent, and the inflation response to the supply shock will remain stronger than the optimal rule. ${ }^{21}$

\subsection{A constant inflation target}

Consider now a constant inflation target $\pi^{b}$ that may differ from the socially optimal inflation rate $\pi^{*}$. The period loss function is then

$$
L_{t}^{b}=\frac{1}{2}\left[\left(\pi_{t}-\pi^{b}\right)^{2}+\lambda\left(y_{t}-y^{*}\right)^{2}\right]
$$

rather than (1.1). It is immediately obvious that only average inflation is affected. Hence, by selecting an inflation target that fulfills

$$
\pi^{b}=\pi^{*}-\frac{\lambda \alpha y^{*}}{1-\beta \rho-\beta \alpha \hat{c}}
$$

\footnotetext{
${ }^{21}$ After this paper was completed I received a paper by Herrendorf (1995) with a related result: For the case without persistence a constant linear inflation contract will result in too high inflation variability, if the natural rate of output is random. Then a 'weight-conservative' central bank may outperform a constant linear inflation contract, and both these alternatives are dominated by a combination of a 'weight-conservative' central bank and a constant linear inflation contract.
} 
the decision rule will be $\left(\pi^{*}, \hat{b}, \hat{c}\right)$. A constant linear inflation contract and a constant inflation target are equivalent.

\subsection{A state-contingent linear inflation contract}

Consider next a state-contingent linear inflation contract, when the added cost of inflation has a marginal cost of inflation that depends on lagged output. Let the added cost of inflation be $\left(f_{0}+f_{1} y_{t-1}\right)\left(\pi_{t}-\pi^{*}\right)$, where $f_{0}$ and $f_{1}$ are constant. The loss function will be

$$
L_{t}^{b}=\frac{1}{2}\left[\left(\pi_{t}-\pi^{*}\right)^{2}+\lambda\left(y_{t}-y^{*}\right)^{2}\right]+\left(f_{0}+f_{1} y_{t-1}\right)\left(\pi_{t}-\pi^{*}\right),
$$

and the decision problem is

$$
V^{b}\left(y_{t-1}\right)=E_{t-1} \min _{\pi_{t}}\left\{\frac{1}{2}\left[\left(\pi_{t}-\pi^{*}\right)^{2}+\lambda\left(y_{t}-y^{*}\right)^{2}\right]+\left(f_{0}+f_{1} y_{t-1}\right)\left(\pi_{t}-\pi^{*}\right)+\beta V^{b}\left(y_{t}\right)\right\}
$$

The first order condition will be

$$
\pi_{t}-\pi^{*}+\lambda \alpha\left(y_{t}-y^{*}\right)+f_{0}+f_{1} y_{t-1}+\beta \alpha V_{y}^{b}\left(y_{t}\right)=0
$$

Taking expectations we see that

$$
\begin{gathered}
\mathrm{E}_{t-1} \pi_{t}=\pi^{*}+\left(\lambda y^{*}-\beta \gamma_{1}\right) \alpha-f_{0}-\left[\left(\lambda+\beta \gamma_{2}\right) \alpha \rho+f_{1}\right] y_{t-1} \\
\frac{\partial \mathrm{E}_{t-1} \pi_{t}}{\partial y_{t-1}}=-\left(\lambda+\beta \gamma_{2}\right) \alpha \rho-f_{1}
\end{gathered}
$$

where I have exploited (3.5). Hence, by selecting

$$
f_{0}=\left(\lambda y^{*}-\beta \gamma_{1}\right) \alpha \text { and } f_{1}=-\left(\lambda+\beta \gamma_{2}\right) \alpha \rho
$$

we can achieve

$$
\mathrm{E}_{t-1} \pi_{t}=\pi^{*} \text { and } c=0
$$


Applying the envelope theorem to (3.30) results in

$$
\begin{gathered}
\gamma_{1}+\gamma_{2} y_{t-1}=\mathrm{E}_{t-1}\left\{\left[\lambda\left(y_{t}-y^{*}\right)+\beta\left(\gamma_{1}+\gamma_{2} y_{t}\right) \rho\right]\left[\rho-\alpha \frac{\partial \mathrm{E}_{t-1} \pi_{t}}{\partial y_{t-1}}\right]+f_{1}\left(\pi_{t}-\pi^{*}\right)\right\} \\
=-\left(\lambda y^{*}-\beta \gamma_{1}\right) \rho+\left(\lambda+\beta \gamma_{2}\right) \rho^{2} y_{t-1}
\end{gathered}
$$

where I have used (3.33). Identifying $\gamma_{1}$ and $\gamma_{2}$ we get (3.9) as in the optimal rule. Combining (3.9) with (3.32) we see that

$$
f_{0}=\frac{\lambda \alpha y^{*}}{1-\beta \rho} \quad \text { and } \quad f_{1}=-\frac{\lambda \alpha \rho}{1-\beta \rho^{2}}
$$

results in the optimal decision rule $\left(\pi^{*}, b^{*}, 0\right)$, regardless of the conditions (3.19) and (3.23).

Thus a state-contingent linear inflation contract can achieve the second-best equilibrium under persistence, as has been shown by Lockwood, Miller and Zhang (1995).

\subsection{A state-contingent inflation target}

Next, consider a state contingent inflation target

$$
\pi^{b}=g_{0}+g_{1} y_{t-1}
$$

where $g_{0}$ and $g_{1}$ are constant. The loss function is

$$
L_{t}^{b}=\frac{1}{2}\left[\left(\pi_{t}-\pi^{b}\right)^{2}+\lambda\left(y_{t}-y^{*}\right)^{2}\right],
$$

and the decision problem is

$$
V^{b}\left(y_{t-1}\right)=\mathrm{E}_{t-1} \min _{\pi_{t}}\left\{\frac{1}{2}\left[\left(\pi_{t}-\pi^{b}\right)^{2}+\lambda\left(y_{t}-y^{*}\right)^{2}\right]+\beta V^{b}\left(y_{t}\right)\right\} .
$$

The first order condition will be

$$
\pi_{t}-\pi^{b}+\lambda \alpha\left(y_{t}-y^{*}\right)+\beta \alpha V_{y}^{b}\left(y_{t}\right)=0,
$$


Taking expectations of (3.39) gives

$$
\mathrm{E}_{t-1} \pi_{t}=g_{0}+\left(\lambda y^{*}-\beta \gamma_{1}\right) \alpha+\left[g_{1}-\left(\lambda+\beta \gamma_{2}\right) \alpha \rho\right] y_{t-1},
$$

where I have used (3.5). Hence, by selecting

$$
g_{0}=\pi^{*}-\left(\lambda y^{*}-\beta \gamma_{1}\right) \alpha \text { and } g_{1}=\left(\lambda+\beta \gamma_{2}\right) \alpha \rho
$$

we can achieve

$$
\mathrm{E}_{t-1} \pi_{t}=\pi^{*} \text { and } \frac{\partial \mathrm{E}_{t-1} \pi_{t}}{\partial y_{t-1}}=0
$$

We know that $b$ is given by (3.15). In order to find $\gamma_{1}$ and $\gamma_{2} I$ apply the envelope theorem to (3.38) which gives

$$
\begin{aligned}
\gamma_{1}+\gamma_{2} y_{t-1} & =\mathrm{E}_{t-1}\left\{-g_{1}\left(\pi_{t}-\pi^{b}\right)+\left[\lambda\left(y_{t}-y^{*}\right)+\beta\left(\gamma_{1}+\gamma_{2} y_{t}\right) \rho\right]\left[\rho-\alpha \frac{\partial \mathrm{E}_{t-1} \pi_{t}}{\partial y_{t-1}}\right]\right\} \\
& =-\left[g_{1}\left(\pi^{*}-g_{0}\right)+\lambda \rho y^{*}-\beta \rho \gamma_{1}\right]+\left[g_{1}^{2}+\left(\lambda+\beta \gamma_{2}\right) \rho^{2}\right] y_{t-1}
\end{aligned}
$$

where I have taken (3.41) into account. Identifying the coefficient for $y_{t-1}$ gives

$$
\gamma_{2}=g_{1}^{2}+\left(\lambda+\beta \gamma_{2}\right) \rho^{2}
$$

Because of (3.40) this is the same equation as (3.17). This means that $\gamma_{1}$ and $\gamma_{2}$ are given by (3.21) with $\hat{c}$ given by (3.20), if and only if the second existence condition (3.23) holds. Thus, with

$$
g_{0}=\pi^{*}-\frac{\lambda \alpha y^{*}}{1-\beta \rho-\beta \alpha \hat{c}} \text { and } g_{1}=\hat{\mathrm{c}}
$$

the decision rule will be $\left(\pi^{*}, \hat{b}, 0\right)$ with $\hat{b}$ given by (3.25). Hence, the inflation bias can be eliminated, but the inflation response to the supply shock will be the same as with a constant inflation target and hence stronger than the optimal rule. An inflation target depending upon $y_{t-1}$ only cannot achieve both the optimal average inflation and the optimal inflation variability. 
Why cannot a state-contingent inflation target induce the optimal rule when a statecontingent linear inflation contract can? Compare the first-order condition for the linear inflation contract, (3.31), and for the inflation target, (3.39). It appears that by selecting

$$
\pi^{b}=\pi^{*}-f_{0}-f_{1} y_{t-1}
$$

it should be possible to induce the optimal rule. This appearance is misleading, though. We can see this by comparing the loss functions in the two cases, assuming (3.44). Then we have

$$
L_{t}^{b}=\frac{1}{2}\left[\left(\pi_{t}-\pi^{*}\right)^{2}+\lambda\left(y_{t}-y^{*}\right)^{2}\right]+\left(f_{0}+f_{1} y_{t-1}\right)\left(\pi_{t}-\pi^{*}\right),
$$

with a linear inflation contract, and

$$
\begin{gathered}
L_{t}^{b}=\frac{1}{2}\left[\left(\pi_{t}-\pi^{b}\right)^{2}+\lambda\left(y_{t}-y^{*}\right)^{2}\right]= \\
\frac{1}{2}\left[\left(\pi_{t}-\pi^{*}\right)^{2}+\lambda\left(y_{t}-y^{*}\right)^{2}\right]+\left(f_{0}+f_{1} y_{t-1}\right)\left(\pi_{t}-\pi^{*}\right)+\frac{1}{2}\left(f_{0}+f_{1} y_{t-1}\right)^{2} .
\end{gathered}
$$

with an inflation target. We see that the loss functions differ by the third term in (3.46). The fact that this output-dependent term enters with an inflation target means that it will be more important to stabilize output, and hence to let inflation react more vigorously to supply shocks. Taking this into account, (3.44) with $f_{0}$ and $f_{1}$ given by (3.32) is not enough to eliminate the average and state-contingent inflation bias; instead (3.36) with $g_{0}$ and $g_{1}$ given by (3.43) is required. In the derivation of the two equilibria above, the difference shows up in different results of the envelope theorem, cf. (3.34) and (3.42). Put differently, the derivatives of the value functions $V_{y}^{b}\left(y_{t}\right)=\gamma_{1}+\gamma_{2} y_{t}$ in (3.31) and (3.39) are not the same; hence the two first-order conditions do not result in the same policy.

Without any supply shocks, that is, with $\epsilon_{t} \equiv 0$, the two regimes would be identical and result in the optimal outcome. Hence we have a lack of certainty equivalence between the two regimes.

The second existence condition (3.23) must hold for the inflation target to have an equilibrium, also when the inflation target is given by (3.43) (unless $y^{*}=0$, in which case 
only the first existence condition (3.19) must hold). With the optimal linear inflation contract the existence conditions need not hold.

Finally, there is nevertheless an intriguing way to achieve the second-best equilibrium with an a state-contingent inflation target, namely by combining the inflation target with a Rogoff 'weight-conservative' central bank. By (3.25) $\hat{b}$ is decreasing in $\lambda$ (note that $\hat{c}$ by (3.20) is decreasing in $\lambda$ ). Then there exists a $\lambda^{b}<\lambda$ such that the corresponding $\hat{b}$ equals the optimal $b^{*}$ (note that $\hat{b} \rightarrow 0$ for $\lambda^{b} \rightarrow 0$.) Thus, if the central bank is assigned a loss function with the appropriate relative weight $\lambda^{b}<\lambda$ and the inflation target (3.43) that corresponds to that relative weight, the optimal rule $\left(\pi^{*}, b^{*}, 0\right)$ will result. Rogoff's (1985) result is thus suitably resurrected. Inflation target regimes should not only have low and possibly state-contingent inflation targets. They should also put extra weight on inflation stabilization.

\subsection{An output target equal to the natural output level}

For completeness I shall also report the results for an "output target" regime where the central bank has the period loss function

$$
L_{t}^{b}=\frac{1}{2}\left[\left(\pi_{t}-\pi^{*}\right)^{2}+\lambda\left(y_{t}-y_{t}^{b}\right)^{2}\right] .
$$

That is, the central bank has an inflation target equal to the socially desirable inflation rate $\pi^{*}$ and an output target equal to $y_{t}^{b}$. These results follow easily from the analysis above.

First, suppose the output target is constant and equal to the natural rate,

$$
y_{t}^{b}=0
$$

(this is the case analyzed by Lockwood and Philippopoulos (1994)). It follows directly from the analysis of discretion above that the decision rule (3.14) will be $\left(\pi^{*}, \hat{b}, \hat{c}\right)$. The equilibrium is the same as for the constant linear inflation contract (3.27) and the constant inflation target (3.28). That is, the average inflation bias is eliminated but there is a state-contingent inflation bias, and inflation variability is higher than optimal. The first 
existence condition (3.19) must hold, but not the second.

It is easily shown that the output target has to equal the state-contingent "short-run" natural output level,

$$
y_{t}^{b}=\mathrm{E}_{t-1} y_{t}=\rho y_{t-1},
$$

in order to achieve the second-best equilibrium $\left(\pi^{*}, b^{*}, 0\right)$. This occurs regardless of the existence conditions (3.19) and (3.23). ${ }^{22}{ }^{23}$

\section{Conclusions}

An inflation target regime is interpreted as the delegation of monetary policy to a central bank that is assigned an explicit inflation target, an implicit output or unemployment target, and an implicit relative weight on output/unemployment stabilization. The paper has shown that, in the static situation without output/unemployment persistence, an inflation target, equal to the socially desirable inflation rate less the discretionary inflation bias, is equivalent to an optimal linear inflation contract. Hence, an inflation target can achieve the second-best equilibrium. It is better to delegate monetary policy to a central bank with a low inflation target, an 'inflation-target-conservative' centralbank, than to a Rogoff 'weight-conservative' central bank. It follows that an optimal inflation target also dominates the escape-clause alternatives suggested by Flood and Isard (1989) and Lohmann (1992).

\footnotetext{
${ }^{22}$ After this paper was completed I received a paper by Lockwood (1995) with related results: For the case without persistence a constant output target equal to the mean natural rate results in too high inflation variability relative to the second-best equilibrium, if the natural rate of output is random and private information to the central bank. Then a Rogoff 'weight-conservative' central bank can improve the equilibrium. Under some assumptions a 'weight-conservative' central bank can also improve equilibria with linear inflation contracts.

${ }^{23} \mathrm{~J}$ on Faust has pointed out that the equivalence between an inflation target and a linear inflation contract with a quadratic loss function is an example of the general property that there is a continuum of general quadratic forms over inflation, output and a constant that as period loss functions result in a decision rule that coincides with the optimal rule under commitment. This general property holds when there is no output persistence, as is easily checked. When there is output persistence, the situation is more complicated in that a state-contingent inflation target is no longer exactly identical to a statecontingent linear inflation contract. Still, the general property must hold also in that case, if lagged output is included in the quadratic form. An examination of the restrictions on the general quadratic form that are needed to induce the second-best equilibrium indicates that the cases with economicly relevant interpretations coincide with the cases discussed in this paper.
} 
A much emphasized empirical implication of Rogoff (1985) is that lower inflation should be associated with increased output variability (if that lower inflation is the result of more 'weight-conservative' central banks. This implication has not received any empirical support, though (cf. Alesina and Summers (1993), Debelle and Fischer (1993) and Stanley Fischer (1994)). Among possible explanations of this the literature (cf. Fischer (1995a)) has suggested that more-independent central banks are better at stabilization than lessindependent banks; that fiscal policy is more disciplined in countries with more central bank independence; or that both inflation and output performance are primarily affected by shocks that differ from country to country. An obvious but nevertheless overlooked alternative explanation is that lower inflation is due to lower inflation targets rather than to increased weights on inflation stabilization!

The equivalence of an appropriately chosen inflation target to a linear inflation contract is of considerable practical importance. A linear inflation contract is difficult to implement, and there does not yet exists an example in the real world of a linear inflation contract. ${ }^{24}$ Inflation targets already exist in the real world, and they seem much easier to implement.

Another practical implication is that an inflation target may serve a useful inflationdampening role also if actual inflation exceeds the target. Indeed, an empirical implication of the inflation bias under discretion is that actual inflation will on average exceed the inflation target. Similarly, the inflation bias implies that an inflation target will normally be imperfectly credible, since inflation expectations will normally exceed the inflation target. So far the inflation targets in the existing inflation target regimes have indeed been imperfectly credible (see Svensson (1993), the papers in Leiderman and Svensson (1995), and Freeman and Willis (1995)). Nevertheless, if the inflation target is sufficiently low, the resulting inflation may be lower than it would have been without the target.

With output persistence, the results above are somewhat modified. The paper shows that a constant (non-contingent) linear inflation contract and constant inflation target are still equivalent. Both can remove the average inflation bias, but they cannot remove the

\footnotetext{
${ }^{24}$ Walsh (1994) examines whether the New Zealand monetary regime can be interpreted as an optimal linear inflation contract and finds that it cannot.
} 
state-contingent part of the inflation bias. Neither can they reduce the too high inflation variability that results under discretion. A state-contingent inflation target can, as can a state-contingent linear inflation contract, in addition remove the state-contingent part of the inflation bias. A state-contingent inflation target cannot, in contrast to a statecontingent linear inflation contract, reduce the inflation variability to the optimal level, but leaves inflation variability too high and output variability too low. Hence, a statecontingent inflation target and a state-contingent linear inflation contract are not fully equivalent. A Rogoff 'weight-conservative' central bank can reduce the inflation variability to the optimal level, and with an appropriate state-contingent inflation target it can also eliminate the inflation bias and achieve the second-best equilibrium.

It follows that, with persistence, for constant inflation targets (and with constant linear inflation contracts) the situation can be also improved (although not all the way to the second-best equilibrium) by assigning an increased weight on inflation stabilization. In general, it seems that central banks should be both 'inflation-target-conservative' and 'weight-conservative'. Rogoff's result is hence suitably resurrected.

Thus, it appears that performance can be improved if real world inflation target regimes not only have low inflation targets, but also have a relatively high weights on inflation stabilization. If the width of the tolerance band for the inflation target indicates the implicit weight on output stabilizations, the bands should then be relatively narrow (which they might actually be, relative to inflation forecast errors, cf. Freedman (1995)).

A general conclusion for the literature on rules and discretion from this paper is that a quadratic loss function has more than one parameter that may warrant discussion. For reasons that ex post appear arbitrary the discussion in the literature has focused almost exclusively on one parameter of the standard quadratic loss function, the relative weight on inflation stabilization, with the occasional observation that a reduction of the output target would improve the situation. Discussion of the inflation target parameter is of no less, and perhaps of more, practical relevance. Thus, the identification of 'conservativeness' with the relative weight on inflation stabilization seems unwarranted. The same can be said about the identification of central bank independence with the same relative weight in the literature on measurement of central bank independence (see Cukierman 
(1992) for discussion of measures of central bank independence and see Debelle and Fischer (1994) and Stanley Fischer (1994) for recent surveys). With the distinction between goal independence and instrument independence, the former is not necessary correlated with the relative weight, and the latter is not necessarily correlated with properties of the goal.

The conclusions above are under the maintained assumption that the implicitly assigned output/unemployment target in the inflation target regime corresponds to less unemployment than the natural rate. This assumptions serves to represent, as outlined in the Introduction, the unfortunate and realistic temptation to err on the lax side in monetary policy. The literature and this paper has shown various ways of mitigating this temptation, normally taking its origin as given. A good rule in economic policy is that distortions should be attacked at their source, if possible. This rule then implies using structural labor market policy to improve the working of labor markets, and, to the extent that the temptation to err on the lax side has other roots, for instance design tax systems and pursue a public debt policy that does not create benefits of surprise inflation. The rule also implies that monetary policy will be inefficient in removing such distortions and should not be assigned such tasks. This in turn has the obvious implication that monetary policy should not be assigned implicit or explicit output/unemployment targets that correspond to lower unemployment than the natural rate. Creating mechanisms for rational assignment of output/unemployment targets should be a crucial aspect in monetary reform. In this regard it is worth observing that only without persistence in output/unemployment is it enough to assign output/unemployment targets corresponding to the long-run natural rate. With persistence, under discretion there is still a statecontingent inflation bias, as well as too high inflation variability relative to the second best. Therefore, a 'weight-conservative' central bank with a state-contingent inflation target, or a state-contingent linear inflation contract, is still needed in order to achieve the second best. Only if the output/unemployment target is state-contingent and corresponds to the short-run natural rate of unemployment can the second best be achieved directly.

The inflation target regime analyzed in the paper has been an idealized regime with a clear delegation of monetary policy to an instrument-independent central bank account- 
able for minimizing an assigned loss function. I have noted above that of the existing inflation target regimes, that in New Zealand comes closest to such a clear delegation. The explicit inflation target regimes in the other countries, Canada, U.K., Sweden and Finland, differ in several respects from that in New Zealand. Since the central banks have less independence, it is a less manifest delegation of monetary policy. The status of the inflation targets is also less. There is no legal mandate for price stability in these other countries. The status of the inflation target seems highest in Canada, where it is an explicit agreement between Bank of Canada and the Government. In the U.K. the inflation target was announced by the Chancellor of Exchequer for the duration of this parliament. There is no delegation since the Chancellor is in charge of monetary policy, although some changes in procedures have made Bank of England marginally more independent (see Bowen (1995)). In Finland and Sweden the inflation targets are unilateral announcements by the central banks. The accountability for fulfilling the inflation targets is not explicit in these countries, and it seems mostly to consist of the embarrassment caused by missing or giving up the target. In contrast, in New Zealand the Governor may be fired if the inflation target is missed. The explicit inflation targets make it easier to monitor and measure the performance of the central banks, though (in the U.K., the combined performance of the Chancellor and Bank of England).

The rational institutional setup of monetary policy in New Zealand may imply an implicit output/unemployment target closer to the natural rate of unemployment, and a lower implicit relative weight on output/unemployment stabilization, compared to the other inflation target regimes. The less independence of the central banks and the lower status of the inflation targets in the other countries make it more likely that the implicit output/unemployment targets are likely to be more ambitious and result in an average inflation bias. The less enforcement of the inflation target also makes it more likely that the implicit weight on output/unemployment stabilization is relatively high. If this is so, we should expect the inflation targets to be less credible (that is, inflation expectations should exceed the targets more) and inflation should be more variable (relative to the variability of the exogenous disturbances) in the other inflation target regimes. Since the inflation target regimes are so recent (none of them has yet gone through a complete 
business cycle), we will have to wait a few years for reliable empirical comparisons.

Finally, I would like to argue that the goal of price stability advocated for monetary policy in practice (almost) always includes an element of output and unemployment stabilization, and that it would be advantageous to make this explicit and transparent rather than implicit, for instance in the following way (cf. Svensson (1994, 1995b)): Formulate the goal for monetary policy as a hierarchy of goals, a so-called lexicographic ordering. Let the primary goal be medium- and long-run price stability. In practice, 'price stability' has become identified with inflation stability around a low or zero mean, that is, base drift in the price level has been accepted. Let me here (temporarily) follow this practice (price level vs. inflation stability is further discussed in some detail in, for instance, Duguay (1993), see also Svensson (1995a)). Let the secondary goal be stabilization of unemployment (when output, employment and unemployment differ, it seems that it is unemployment that should be stabilized, assuming that social welfare is concave in unemployment) around the short-run natural rate of unemployment, where it is understood that such stabilization should only be attempted as long as the primary goal is not endangered. This hierarchy of goals can then be interpreted as implying that some short-run fluctuations in the inflation rate around the medium- and long-run mean is allowed in order to dampen short-run unemployment fluctuations (around the short-run natural rate), which in turn is consistent with a loss function of the form (1.2) with the unemployment target set equal to the short-run natural rate. ${ }^{25}$

\footnotetext{
${ }^{25}$ The primary goal could even be interpreted as adding the condition that the unconditional mean of inflation fulfills $\mathrm{E}\left[\pi_{t}\right]=\pi^{b}$ to (1.2), in which case the average inflation bias should vanish even if the unemployment target is below the long-run natural rate.

The hierarchical formulation is consistent with the well-known formulation of Bundesbank's objectives in the Law concerning the Bundesbank (cf. Bank for International Settlements (1963, p. 57 and 59)). The law states that the Bundesbank shall "regulate the money circulation and the supply of credit to the economy with the aim of safeguarding the currency" (interpret as primary goal), and that the Bundesbank is bound to "support the general economic policy of the Federal Government, but only in so far as this is consistent with its duty of safeguarding the currency" (interpret as secondary goal). The Bundesbank has indeed instituted an element of automatic output stabilization in that the monetary targets are set consistent with a velocity forecast, a 2 percent inflation target, and a forecast of potential output rather than actual output (von Hagen (1995)).
} 


\section{Appendix}

Consider the explicitly recursive problem

$$
V_{t-1}\left(y_{t-1}\right)=\mathrm{E}_{t-1} \min _{\pi_{t}}\left\{\frac{1}{2}\left[\left(\pi_{t}-\pi^{*}\right)^{2}+\lambda\left(y_{t}-y^{*}\right)^{2}\right]+\beta V_{t}\left(y_{t}\right)\right\}
$$

instead of (3.11). Let $V_{t}\left(y_{t}\right)=\gamma_{0 t}+\gamma_{1 t} y_{t}+\gamma_{2 t} y_{t}^{2}$. The first-order condition results in a decision rule of the form $\pi_{t}=a_{t}-b_{t} \epsilon_{t}-c_{t} y_{t-1}$, with

$$
a_{t}=\pi^{*}+\left(\lambda y^{*}-\beta \gamma_{1 t}\right) \alpha, \quad b_{t}=\frac{\left(\lambda+\beta \gamma_{2 t}\right) \alpha}{1+\left(\lambda+\beta \gamma_{2 t}\right) \alpha^{2}} \quad \text { and } \quad c_{t}=\left(\lambda+\beta \gamma_{2 t}\right) \alpha \rho
$$

The envelope theorem applied to (5.1) results in

$$
\gamma_{2, t-1}=\rho^{2}\left(\lambda+\beta \gamma_{2 t}\right)+\alpha^{2} \rho^{2}\left(\lambda+\beta \gamma_{2 t}\right)^{2} .
$$

Using the expression for $c_{t}$ in (5.2) the equation can be written in terms of $c_{t}$ as

$$
c_{t-1}=\lambda \alpha \rho+\beta \rho^{2} c_{t}+\beta \alpha \rho c_{t}^{2} .
$$

A stationary solution $c_{t-1}=c_{t}=c$ must fulfill the second-degree equation

$$
c^{2}-\frac{1-\beta \rho^{2}}{\alpha \beta \rho} c+\frac{\lambda}{\beta}=0 .
$$

which has real solutions

$$
c=\frac{1}{2 \beta \alpha \rho}\left[1-\beta \rho^{2} \pm \sqrt{\left(1-\beta \rho^{2}\right)^{2}}-4 \lambda \beta \alpha^{2} \rho^{2}\right]>0
$$

if and only if (3.19) is fulfilled.

We know that $\rho=0$ by (5.4) implies that $c=0$, and that $\beta=0$ implies $c=\lambda \alpha \rho$. Then the smaller solution (3.20) is the relevant one, since only then does $c \rightarrow 0$ when $\rho \rightarrow 0$, and $c \rightarrow \lambda \alpha \rho$ when $\beta \rightarrow 0$. Alternatively, one can study the iteration (5.4) when $t \rightarrow-\infty$ and show that the smaller solution is the stable one. 
The envelope theorem applied to (5.1) also results in

$$
\gamma_{1, t-1}=-\lambda y^{*}\left(\rho+\alpha c_{t}\right)+\beta\left(\rho+\alpha c_{t}\right) \gamma_{1 t}
$$

Alternatively, the recursion can by (5.2) be written in terms of $a_{t}$,

$$
a_{t-1}=\pi^{*}+\lambda \alpha y^{*}-\beta\left(\rho+\alpha c_{t}\right) \pi^{*}+\beta\left(\rho+\alpha c_{t}\right) a_{t}
$$

We realize that for $\gamma_{1, t}$ and $a_{t}$ to converge towards $\gamma_{1}$ and $a$ we need the condition (3.22) to hold. This condition is not automatically fulfilled if (3.19) is fulfilled. For instance, if $\lambda=\bar{\lambda}_{1}, \hat{c}=\frac{1-\beta \rho^{2}}{2 \beta \alpha \rho}$. If $\rho \rightarrow 1, \hat{c} \rightarrow \frac{1-\beta}{2 \beta \alpha}$. But $\beta\left(1+\alpha \frac{1-\beta}{2 \beta \alpha}\right)=\frac{3+1}{2} \geq 1$ if $\beta \geq \frac{1}{2}$.

More precisely, note that

$$
\bar{\lambda}_{1}-\bar{\lambda}_{2}=\frac{\left(1-\beta \rho^{2}\right)^{2}-4(1-\beta \rho)\left(\rho-\rho^{2}\right)}{4 \beta \alpha^{2} \rho^{2}} .
$$

Let $x=\beta \rho$ and study the numerator

$$
z=(1-x \rho)^{2}-4(1-x)\left(\rho-\rho^{2}\right)
$$

For $0<\beta<1$ and $0<\rho<1$ it is easy to show that $z \geq 0$ and that $z=0$ if and only if $x=2-\frac{1}{\rho}$, which occurs if and only if $0<\rho=\frac{1-\sqrt{1-\beta}}{\beta}<1$. Thus (3.24) must hold.

\section{References}

Alesina, Alberto, and Lawrence H. Summers (1993), "Central Bank Independence and Macroeconomic Performance: Some Comparative Evidence," Journal of Money, Credit and Banking 25, 151-162.

Ammer, John, and Richard T. Freeman (1995), "Inflation Targeting in the 1990s: The Experiences of New Zealand, Canada and the United Kingdom," Journal of Economics and Business 47, 165-192.

Archer, David (1995), "Rules for Monetary Policy: The Rationale Underlying the New 
Zealand Approach," paper presented to the Swiss National Bank Conference on Rules versus Discretion in Monetary Policy, March 15-19, Gerzensee, Switzerland.

Bank of International Settlements (1963), Eight European Central Banks, George Allen and Unwin, London.

Barro, Robert, and David Gordon (1983), "A Positive Theory of Monetary Policy in a Natural Rate Model," Journal of Political Economy 91, 589-610.

Blanchard, Olivier, and Lawrence H. Summers (1986), "Hysteresis and European Unemployment," NBER Macroeconomics Annual 1.

Bowen, Alex (1995), "British Experience with Inflation Targetry," in Leonardo Leiderman and Lars E.O. Svensson, eds., Inflation Targets, CEPR, London.

Canzoneri, Matthew B. (1985), "Monetary Policy Games and the Role of Private Information," American Economic Review 75, 1056-1070.

Canzoneri, Matthew B., Charles Nolan and Anthony Yates (1995), "Mechanisms for Achieving Monetary Stability: Inflation Targeting vs. the ERM," Working Paper, Bank of England.

Cukierman, Alex (1992), Central Bank Strategy, Credibility and Independence, MIT Press, Cambridge, MA.

Currie, David, Paul Levine and Joseph Pearlman (1995), "Can Delegation be Counterproductive? The Choice of 'Conservative' Bankers in Open Economies," CEPR Discussion Paper No. 1148.

Debelle, Guy, and Stanley Fischer (1994), "How Independent Should a Central Bank Be?" in Jeffrey C. Fuhrer, ed., Goals, Guidelines and Constraints Facing Monetary Policymakers, Federal Reserve Bank of Boston, 1994.

Duguay, Pierre (1993), "Some Thoughts on Price Stability versus Zero Inflation," Working Paper, Bank of Canada. 
Ferstman, Chaim, and Kenneth L. Judd (1987), "Equilibrium Incentives in Oligopoly," American Economic Review 77, 927-940.

Fischer. Andreas M. (1995), "New Zealand's Experience with Inflation Targets," in Leonardo Leiderman and Lars E.O. Svensson, eds., Inflation Targets, CEPR, London.

Fischer, Stanley (1994), "Modern Central Banking," in Forrest Capie, Charles Goodhart, Stanley Fischer and Norbert Schnadt, The Future of Central Banking, Cambridge University Press, Cambridge, U.K.

Fischer, Stanley (1995a), "Central-Bank Independence Revisited," American Economic Review 77, 927-940.

Fischer, Stanley (1995b), "The Unending Search for Monetary Salvation," NBER Macroeconomics Annual 10, forthcoming.

Flood, Robert F., and Peter Isard (1989): "Monetary Policy Strategies," IMF Staff Papers 36, 612-632.

Fratianni, Michele, Jürgen von Hagen and Christopher Waller (1993), "Central Banking as a Political Principal-Agent Problem," Economic Inquiry, forthcoming.

Freeman, Richard T., and Jonathan L. Willis (1995), "Targeting Inflation in the 1990s: Recent Challenges," Working Paper, Federal Reserve Board, Washington, D.C.

Freedman, Charles (1995), "The Canadian Experience with Targets for Reducing and Controlling Inflation," in Leonardo Leiderman and Lars E.O. Svensson, eds., Inflation Targets, CEPR, London.

Goodhart, Charles A.E. (1994), "What Should Central Banks Do? What Should Be Their Macroeconomic Objectives and Operations?" Economic Journal, 104, 14241436 .

Goodhart, Charles A.E., and José Viñals (1994), "Strategy and Tactics of Monetary Policy: Examples from Europe and the Antipodes," in Jeffrey C. Fuhrer, ed., Goals, 
Guidelines and Constraints Facing Monetary Policymakers, Federal Reserve Bank of Boston.

Gottfries, Nils, and Henrik Horn (1987), "Wage Formation and the Persistence of Unemployment," Economic Journal 97, 877-994.

Herrendorf, Berthold (1995), "A Feasible Employment Contract for a Conservative Central Banker," Working Paper, European University Institute, Florence.

Jonsson, Gunnar (1995), "Monetary Politics and Unemployment Persistence," in Gunnar Jonsson, Institutions and Incentives in Monetary and Fiscal Policy, IIES Monograph No. 29 , chapter 4.

King, Mervyn (1995), "Changes in UK Monetary Policy: Rules and Discretion in Practice," paper presented to the Swiss National Bank Conference on Rules versus Discretion in Monetary Policy, March 15-19, Gerzensee, Switzerland.

Kydland, Finn, and Edward Prescott (1977), "Rules Rather Than Discretion: The Inconsistency of Optimal Plans," Journal of Political Economy 85, 473-490.

Laidler, David (1993), "Price Stability and the Monetary Order," in Kumihara Shigehara, ed., Price Stabilization in the 1990s, Macmillan, London, 331-356.

Leiderman, Leonardo, and Lars E.O. Svensson, eds. (1995), Inflation Targets, CEPR, London.

Lockwood, Ben (1995), "Rogoff's Conservative Central Banker Restored: Asymmetric Information and the Delegation of Monetary Policy," Working Paper, University of Exeter.

Lockwood, Ben, and Apostolis Philippopoulos (1994), "Insider Power, Unemployment Dynamics and Multiple Inflation Equilibra," Economica 61, 59-77.

Lockwood, Ben, Marcus Miller and Lei Zhang (1995), "Designing Monetary Policy when Unemployment Persists," Working Paper, University of Exeter. 
Lohmann, Susanne (1992), "The Optimal Degree of Commitment: Credibility and Flexibility," American Economic Review 82, 273-286.

McCallum, Bennett (1995), "Two Fallacies Concerning Central-Bank Independence," American Economic Review 85, 207-211.

Obstfeld, Maurice (1991), "Destabilizing Effects of Exchange Rate Escape Clauses," NBER Working Paper No. 3603.

Persson, Torsten, and Guido Tabellini (1990), Macroeconomic Policy, Credibility and Politics, Harwood, London.

Persson, Torsten, and Guido Tabellini (1994), "Designing Institutions for Monetary Stability," Carnegie-Rochester Conference Series on Public Policy 39, 53-84.

Rogoff, Kenneth (1985), "The Optimal Degree of Commitment to a Monetary Target," Quarterly Journal of Economics 100, 1169-1190.

Svensson, Lars E.O. (1993), "The Simplest Test of Inflation Target Credibility," NBER Working Paper No. 4604.

Svensson, Lars E.O. (1994), Penningpolitiska Alternativ för Sverige (Monetary Policy Alternatives for Sweden, in Swedish), Norstedts, Stockholm.

Svensson, Lars E.O. (1995a), "Price Level Targeting vs. Inflation Targeting," in preparation.

Svensson, Lars E.O. (1995b), "The Swedish Experience of an Inflation Target," in Leonardo Leiderman and Lars E.O. Svensson, eds. (1995), Inflation Targets, CEPR, London.

von Hagen, Jürgen (1995), "Inflation and Monetary Targeting in Germany," in Leonardo Leiderman and Lars E.O. Svensson, eds., Inflation Targets, CEPR, London.

Walsh, Carl (1994), "Is New Zealand's Reserve Bank Act of 1989 an Optimal Central Bank Contract?" Journal of Money, Credit and Banking, forthcoming. 
Walsh, Carl (1995a), "Optimal Contracts for Independent Central Bankers," American Economic Review 85, 150-167.

Walsh, Carl (1995b), "Recent Central Bank Reforms and The Role of Price Stability as the Sole Objective of Monetary Policy, ${ }^{n}$ NBER Macroeconomics Annual 10, forthcoming. 